\title{
LA CONVERGENCIA DE LA EDUCACIÓN SUPERIOR EN AMÉRICA LATINA Y SU ARTICULACIÓN CON LOS ESPACIOS EUROPEO E IBEROAMERICANO. POSIBILIDADES Y LÍMITES ${ }^{1}$
}

\author{
Norberto Fernández Lamarra* ${ }^{*}$ UnTREF) $^{2}$
}

Recebido em: 10 de março de 2010

Aprovado em: 02 de abril de 2010

*Especialista, investigador y consultor nacional e internacional en el área de las políticas, la planificación y la gestión de la educación, con énfasis en los últimos años en la educación superior.

Resumen: En el artículo se plantea que la convergencia y articulación de los sistemas de educación superior en América Latina y la consolidación de un Espacio Común que abarque al conjunto del continente, se constituye en un desafío significativo y un proceso ineludible frente a la situación de fragmentación que se registra y la etapa necesaria para la conformación de un Espacio Iberoamericano que no conduzca a una posible situación de carácter neo-colonial. Se caracteriza brevemente la situación actual y la evolución reciente de la educación superior en América Latina y se reseñan los principales programas de convergencia registrados en el marco de los procesos de integración regional. Se analizan los programas, proyectos, trabajos y estudios del MERCOSUR, de la Comisión Europea, del IESALC de la UNESCO, de la OEI, de la OUI, de la RIACES y de algunas de las redes de universidades existentes. Finalmente, se plantean algunas propuestas para atender al desafío de consolidar el Espacio Latinoamericano de Educación Superior y su posible articulación con el Iberoamericano y el Europeo.

Palavras clave: Educación superior - América Latina. Convergencia. Espacios Europeo e Iberoamericano

THE CONVERGENCE OF HIGHER EDUCATION IN LATIN AMERICA AND ITS

INTERACTION WITH THE EUROPEAN AND AMERICAN SPACE. POSSIBILITIES AND LIMITS

\begin{abstract}
The article argues that the convergence and coordination of higher education systems in Latin America and the consolidation of a common area covering the whole continent, constitutes a significant challenge and an inevitable process faced with the situation of fragmentation that is recorded and the necessary stage for the formation of a Latin American Area that does not lead to a possible situation of neo-colonial character. The current situation and recent developments in higher education in Latin America are briefly characterized and the main convergence progra$\mathrm{ms}$ registered in the framework of regional integration processes are outlined. We analyze the programs, projects, works and studies of MERCOSUR, the European Committee, the UNESCO IESALC of the OEI, the OUI, the RIACES and some networks of existing universities. Finally, some proposals are made to address the challenge of consolidating the Latin American Space of Higher Education and its possible links with the Iberian-American and European space.
\end{abstract}

Key words: Higher education - Latin America. Convergence. European and American Space.

\footnotetext{
1 Texto de la exposición a ser presentada en el Panel Organismos transnacionales, estrategias de integración y políticas de educación superior en el contexto iberoamericano, del Seminario Internacional de Políticas Educativas Iberoamericanas. Tendencias, desafíos y compromisos, organizado por el proyecto CYTEDRIAIPE y la Universidad de Barcelona, Barcelona, mayo de 2010.

2 Norberto Fernández Lamarra es Director de Posgrados de la Universidad Nacional de Tres de Febrero (UNTREF) donde, además, dirige el Núcleo Interdisciplinario de Formación y Estudios para el Desarrollo de la Educación, el Programa de Posgrados en Políticas y Administración de la Educación (Maestría y Especializaciones) y el Programa Interinstitucional de Doctorado en Educación UNTREF/UNLa.
} 


\section{EVOLUCIÓN DE LA EDUCACIÓN SUPERIOR EN AMÉRICA LATINA}

Los sistemas de educación superior han registrado en las dos últimas décadas un proceso de fuerte diversificación -tanto en su organización como en su calidad- con la inclusión de modelos universitarios diferentes y contradictorios. Esta situación es claramente diferente a lo que había ocurrido hasta la década del 80: hasta ese momento la educación superior había sido predominantemente estatal y con fuerte autonomía institucional y académica de las universidades, a partir del Movimiento de la Reforma Universitaria originado en la Universidad Nacional de Córdoba, Argentina, en el año 1918. El modelo predominante era el "napoleónico", en el que las facultades de carácter profesional se constituían en el centro de la organización universitaria. En ese modelo, las carreras profesionales son largas, de tipo túnel -como las denominan los europeos-, en las que los alumnos obtienen el título luego de 6 o 7 años de estudios y no existen ciclos ni títulaciones intermedias.

A lo largo de casi todo el siglo XX, el modelo "napoleónico" de universidad y las concepciones de autonomía universitaria y de primacía de la universidad pública se fueron afianzando en la mayor parte de los países latinoamericanos. El número de instituciones universitarias -fundamentalmente estatales- fue creciendo gradualmente y los niveles de calidad se mantuvieron relativamente homogéneos hasta la década del 80.

Hacia fines de esa década e inicios de la del 90, se introdujeron en el marco de los procesos de globalización, estrategias de carácter neoliberal que tendieron a reemplazar las políticas de bienestar impulsadas por el Estado por otras en que predominaban las concepciones de mercado y de privatización de los servicios públicos, entre ellos la educación. Las crisis nacionales en materia económica llevaron a una fuerte restricción del financiamiento público para los sectores sociales, en general, y para la educación y la universidad, en particular.

A pesar de esto, se acrecentó la demanda de educación superior por parte de la población, incrementándose fuertemente las tasas de escolarización y el número de estudiantes. Para atender estas demandas crecientes se fueron creando diversos tipos de instituciones de educación superior universitaria y no universitaria -en su mayoría de carácter privado- y sin criterios previos en cuanto a niveles de calidad y de pertinencia institucional. La educación superior en América Latina registró importantes incrementos desde la segunda mitad del siglo XX: así el número de instituciones universitarias pasó de 75 en 1950 a más de 3.000 actualmente, las que en su mayoría son privadas. El número 
de estudiantes pasó de 276.000 en 1950 a casi 15 millones en la actualidad; es decir, que la matrícula se multiplicó por 55 veces.

La tasa de incremento anual de la matrícula desde 1990 ha sido del 6\%. Esta tasa ha sido mucho mayor para la universidad privada $(8 \%)$ que para la pública $(2,5 \%)$ Esto ha llevado a que actualmente más del $60 \%$ de la matrícula universitaria en América Latina concurra a universidades privadas, a diferencia de lo que ocurría hasta la década del 80 en que la universidad latinoamericana era predominantemente estatal, como ya fue señalado.

En síntesis, se registró un fuerte crecimiento de la matrícula y del número de instituciones de educación superior, una clara tendencia al incremento de las instituciones privadas, una gran diversificación institucional y una alta disparidad en los niveles de calidad.

Conjuntamente con la diversificación institucional y la disparidad en relación con la calidad, aparece una gran heterogeneidad en materia de modelos universitarios, que se constituyen más como "deformaciones" del modelo napoleónico que como superadores del mismo. Se podría plantear que, en muchos casos, se mantienen y se profundizan ciertos aspectos negativos del modelo profesionalista por facultades y se introducen algunos de los aspectos menos deseables de los múltiples modelos vigentes en Estados Unidos. Así se crean en muchos países de América Latina instituciones universitarias privadas que son denominadas "universidades garage" o"universidades patito", por sus dimensiones, por su baja calidad y por el tipo de infraestructura física disponible. En algunos países es difícil actualizar la información sobre el número de instituciones de educación superior existentes por la falta de registros adecuados. El propio Instituto Internacional para la Educación Superior en América Latina y el Caribe (IESALC) de la UNESCO no ha podido disponer hasta ahora de información regional precisa sobre el número de instituciones de este nivel existentes.

A esta caótica heterogeneidad institucional, se agrega la fuerte disparidad en materia de planes de estudio, con denominaciones de titulaciones muy diversas y con objetivos formativos y, por ende, duración de los estudios muy disímiles. Así, se encuentran en un mismo país denominaciones muy diferentes de las titulaciones de una misma área profesional y, a su vez, duraciones también distintas de una misma carrera profesional. ${ }^{3}$

3 En la Argentina en el año 2002 las 92 universidades oficiales y privadas existentes, otorgaban 4219 títulos -muchos de ellos similares- entre los de grado y los de pregrado. La educación superior terciaria $-\mathrm{O}$ no universitaria- ofrecía otros 6965 títulos por lo que el total de títulos ofrecidos por la educación superior argentina era de 11.184. Fuente: Norberto Fernández Lamarra, La educación superior argentina en debate, Eudeba/IESALC-UNESCO, Buenos Aires, mayo de 2003. 
Durante la década del 90 se registró en toda América Latina y con mayor énfasis en algunos países -entre ellos, Argentina, Chile, Colombia y Brasil- una fuerte expansión de los postgrados, en especial de maestrías. Esto significó la incorporación de un nuevo ciclo en los ya heterogéneos modelos -el de las maestrías provenientes en especial de Estados Unidos- sin una modificación sustancial de los objetivos y de la duración del primer ciclo de carácter profesional. Es decir, se registró una superposición de dos modelos: el "napoleónico", profesionalista, de carreras de grado largas con el angloamericano de maestrías posteriores a un ciclo corto, de cuatro años, como el Bachellor.

Si bien no hay información actualizada sobre el crecimiento de la matrícula de los postgrados ${ }^{4}$, se puede afirmar que han tenido un muy fuerte desarrollo cuantitativo en relación con el número de postgrados y de estudiantes. Así, en la Argentina, el número total de carreras de postgrado pasó de 792 en 1994, a 1054 en 1996, a 1642 en 1999, a 2151 en 2003, a 2376 en 2005 y, probablemente, a más de 3000 actualmente.

Este fuerte crecimiento de los postgrados -en especial de las maestrías- sin modificar el grado ha generado una confusión entre los objetivos formativos de las carreras de grado y de postgrado, ya que la mayoría de los postgrados tienen una orientación profesionalista, relativamente similar a la mayor parte de las ofertas académicas de grado.

A su vez, este crecimiento de los postgrados en muy pocos años ha contribuido a una aún mayor heterogeneidad de los niveles de calidad -como ha ocurrido con el grado- y ha llevado a incluir su evaluación y acreditación en los procesos de aseguramiento de la calidad puestos en marcha en los últimos años en casi todos los países de América Latina.

Frente a este panorama brevemente reseñado, surgen con énfasis en América Latina los procesos de aseguramiento de la calidad a través de la evaluación de instituciones y de la acreditación de carreras de grado y de postgrado. ${ }^{5}$

\section{LOS PROCESOS DE CONVERGENCIA EN AMÉRICA LATINA}

\subsection{La necesidad de la convergencia}

Como ya ha sido señalado con anterioridad, hay una falta de convergencia en las políticas de educación superior en América Latina por la influencia de

4 El IESALC de la UNESCO está llevando a cabo actualmente una serie de estudios sobre los procesos de evaluación y acreditación de los postgrados , lo que posibilitará disponer de mayor información y documentación sobre estos procesos.

5 En este trabajo se utilizarán los términos vigentes en la Argentina: las carreras de primer título (undergraduate) se denominan de grado (en otros países de América Latina de pregrado) y los posteriores al primer título de postgrado (posgraduate) 
modelos muy distintos, muy puntuales, muy heterogéneos. Se registra una fuerte divergencia en cuanto a lo institucional: existen desde grandes y tradicionales universidades hasta muy pequeñas instituciones que, en algunos países de América Latina, se conocen -como ya se señaló- como universidades "garage". También se dan situaciones diversas en materia de calidad de la educación superior y de su evaluación, con influencias heterogéneas en materia de diseño y organización de las carreras de grado y postgrado y de educación a distancia y virtual. En este marco, aparece, asimismo la educación transnacional, sin regulaciones y ni controles adecuados $\mathrm{y}$, también, con modelos muy disímiles.

En cuanto al diseño de los modelos académicos, como ha sido señalado, se ha producido también cambios sustantivos: hasta los años 1970-1980 había un predominio de carreras profesionales de modelo napoleónico. A partir de esos años se registró una ampliación y diversificación de la oferta con criterios académicos distintos, a veces contradictorios: por ejemplo, la supervivencia de las carreras tradicionales largas - "carreras túneles" en términos del lenguaje europeo- con seis años formales y ocho reales frente a carreras más cortas y de dudosa "profesionalidad". En otras áreas se definen los títulos de manera poco tradicional. En la Argentina, por ejemplo, en el área de ingeniería, hay más de cien títulos diferentes de ingeniero. Se observa así la supervivencia de distintos modelos. En general, las carreras se conforman por adiciones, agregado a o parches que vienen de estos diversos orígenes y muestran, por lo tanto, influencias disímiles y contrapuestas. Esto causa dificultades para la compatibilidad, para la convergencia y, también, para la movilidad de los estudiantes ante este panorama tan fragmentado. De ahí la necesidad de debatir sobre objetivos académicos, alcance de los títulos y articulación institucional.

Como ha sido ya planteado, más recientemente se han desarrollado las carreras de posgrado con fuerte influencia del modelo del "master" norteamericano. Como se ha visto, han tenido un gran desarrollo en pocos años, pero sin que se haya modificado sustancialmente el grado. Por lo tanto, se produce cierta incompatibilidad y confusión de roles entre el grado y el posgrado; una presencia cada vez más significativa de ofertas extranjeras, como producto de la educación transnacional, sin regulaciones adecuadas. en varios países. Por ejemplo, en la Argentina, las carreras de grado son largas y también lo son los posgrados. Se ha estimado que los ocho o nueve años formales para el grado y la maestría se transforman en doce o más reales. De ahí entonces la necesidad de replantear la articulación del grado y del posgrado en cuanto al alcance de los títulos, a los niveles de formación, a la habilitación profesional, a la dife- 
renciación o no entre carreras académicas y profesionales. En Argentina y en algunos otros países de América Latina -por suerte no es una situación común en toda la región- hay un escaso desarrollo en el nivel de doctorado, lo que afecta el desarrollo académico deseable.

\subsection{Algunos procesos de integración regional en marcha}

Los procesos de integración regional que se vienen registrando en los países de América Latina en las últimas décadas han planteado la necesidad de atender a la articulación y a la convergencia de los sistemas y particularmente en cuanto al reconocimiento de títulos y estudios a fin de posibilitar la movilidad de las personas en el marco de cada región.

Uno de estos procesos ha sido el de la integración del MERCOSUR con Argentina, Brasil, Paraguay y Uruguay como fundadores y la posterior incorporación de Bolivia y Chile como asociados; recientemente ha solicitado su incorporación Venezuela. Otro de los procesos es el del NAFTA con la integración de México con Estados Unidos y Canadá. En Centroamérica se han registrado avances a pesar de los problemas políticos que dificultaron en décadas anteriores la consolidación de la región. Los países andinos tuvieron también dificultades para consolidar el Pacto Andino, que funcionó aceptablemente bien hasta fines de la década del 70 e inicios de la del 80; en estos países es de destacar la organización y funcionamiento del Convenio Andrés Bello para atender a los aspectos de articulación en materia de educación y cultura pero que no ha avanzado significativamente en materia de educación universitaria.

Estos procesos de integración regional son indicadores muy positivos hacia una meta deseable y necesaria y que fue -al inicio de los procesos de independencia de los países latinoamericanos- un muy loable ideal del Libertador Simón Bolívar: la unidad de América Latina. Casi dos siglos después, es de esperar que estos procesos de integración regional coadyuven a estos propósitos, ahora casi imprescindibles frente a la globalización e internacionalización de los aspectos políticos, sociales, económico-productivos, culturales y educativos a nivel mundial.

En el punto 3 de este trabajo se desarrollará lo referido a los procesos de convergencia y articulación en educación en el ámbito del MERCOSUR, particularmente en cuanto a acreditación de carreras universitarias. Los avances en esta región pueden ser de utilidad para otras de América Latina.

\subsection{Otros programas y proyectos de convergencia}

En los últimos años diversos organismos de cooperación internacional regional o bilateral han iniciado programas y proyectos que han promovido la 
convergencia y la articulación entre los sistemas de educación superior. Entre ellos, se pueden citar la UNESCO -particularmente a través del IESALC-; la OEI, la Organización Universitaria Interamericana (OUI), -en especial a través del Instituto de Gestión y Liderazgo Universitario (IGLU)-; la Comisión Europea -especialmente a través de los proyectos ALFA y ALBAN-; los organismos de cooperación de países como España, Francia, Estados Unidos, Canadá, etc.; Columbus; etc.

También se organizaron redes interuniversitarias o ínteragenciales que han coadyuvado a estos propósitos de convergencia: el Grupo Montevideo, la UDUAL, el CSUCA, la Red Columbus, la Red Latinoamericana de Cooperación Universitaria, la Asociación de Universidades de América Latina y el Caribe para la Integración (AUALCPI), la Asociación ORION, la Red Iberoamericana para la Acreditación de la Calidad de la Educación Superior (RIACES), la Red de Macro Universidades Públicas de AL y el Caribe, , la Asociación de Universidades Amazónicas (UNAMAZ), el CRISCOS con las universidades de la región Centro-Oeste de Sudamérica, la Red de Universidades Regionales (UREL), la de las Universidades de la Compañía de Jesús en América Latina (AUSJAL), la que agrupa a las de carácter tecnológico (AIESTALC), la de las Universidades Privadas de Centroamérica (AUPRICA), el CINDA con sede en Chile, la Red RICES para la convergencia de la Educación Superior, etc.

A partir de la CRES/UNESCO, realizada en Cartagena de Indias, Colombia en junio de 2008, se creó una red de redes, ENLACES, en el marco del IESALC/UNESCO, que agrupa a la mayoría de estas redes. La organización de ENLACES se consolidó en un reunión de la gran mayoría de estas redes en Lima, Perú, en junio de 2009.

En el punto 4 se caracterizarán brevemente algunos de estos programas y proyectos de convergencia y articulación.

\section{CONVERGENCIA Y ARTICULACIÓN EN EL ÁMBITO DEL MERCOSUR DEL MECANISMO EXPERIMENTAL DE ACREDITACIÓN DE CARRERAS (MEXA) AL ARCU-SUR}

\subsection{Antecedentes del MEXA}

El MERCOSUR incluyó desde su inicio al Área Educación entre sus aspectos prioritarios e instituyó a la Reunión de Ministros de Educación (RME) como ámbito de decisiones sobre esta temática. Desde su primer Plan Trienal 
de Educación se planteó el reconocimiento y acreditación de estudios y títulos entre sus objetivos principales, para posibilitar la movilidad de las personas dentro de la Región. Esta característica de "precocidad" en cuanto a la consideración de los aspectos educativos en el proceso de integración regional ha sido reconocida por múltiples especialistas, incluso europeos. (FERNÁNDEZ LAMARRA, PULFER, 1992, LÉMEZ, 2002)

En tal sentido avanzó más rápidamente en relación con el reconocimiento de títulos y estudios para la educación primaria o básica y para la enseñanza media general y técnica, ya que estos procesos de reconocimiento eran más sencillos. Como señala Lémez se adoptó un criterio de "construcción" de carácter gradual, de "abajo hacia arriba", de planteamiento y solución de problemáticas de complejidad creciente. Simultáneamente con la aprobación de los protocolos de títulos y estudios para los niveles primario y medio, se establecieron paradigmas compatibles en temas significativos para el proceso de integración, como son los referidos a la enseñanza de la historia y la geografía. ${ }^{6}$

Las dificultades para el reconocimiento de los títulos y estudios de nivel superior derivan de las estrechas y complejas vinculaciones existentes entre la validación de los títulos profesionales y el ejercicio de las respectivas profesiones, ya que -como señala Lémez- responden a lógicas diferentes, muchas veces opuestas al espíritu "aperturista" del Sector Educación y que involucran a actores nacionales de muy diversa índole, con representaciones e intereses muy disímiles. En un Estudio llevado a cabo para la Organización Internacional para las Migraciones (OIM) se han analizado los mecanismos y situaciones diferentes existentes en Argentina, Brasil, Paraguay y Uruguay con respecto a las habilitaciones para el ejercicio profesional con el funcionamiento de consejos profesionales de muy diversa estructuración en Argentina y Brasil y la no existencia de los mismos en Paraguay y Uruguay. (FERNÁNDEZ LAMARRA, 1999). Por otra parte, lo referido a estos temas de Servicios Personales en la Región depende de un Grupo de Trabajo del Consejo del Mercado Común y la RME no tiene incumbencias en ellos.

Esta discusión enrareció los debates y dificultó, en un principio, su análisis hasta que paulatinamente, a partir de acuerdos tácitos al principio y luego en forma explícita, se decidió abocarse a su resolución desde distintos ángulos y perspectivas y diferentes niveles de especificidad. (LÉMEZ, 2002)

6 En una investigación dirigida por el autor en el ámbito de la Universidad Nacional de La Plata se estudiaron los programas de historia y geografía y los libros de texto para los niveles primario y medio de los países del MERCOSUR, estableciéndose los importantes "vacíos" temáticos y las fuertes discrepancias en las explicaciones e interpretaciones de los mismos hechos históricos y geográficos en cada uno de los sistemas educativos 
Se asumió que el reconocimiento de títulos y estudios universitarios tenía dos objetivos principales: uno era de carácter académico para posibilitar la continuación de estudios, el cursado de posgrado y el desempeño de actividades académicas; el otro, era el de habilitar el ejercicio profesional en otro país diferente al que otorgó el título. El primero era más simple y se pudo avanzar en forma concreta; el segundo era más complejo porque se relaciona con el rol del Estado y su obligación de asegurar la formación recibida para habilitar el desempeño profesional, más aún cuando se trate de profesiones que se vinculan con la salud, los bienes de los habitantes y la seguridad. En relación con este segundo objetivo se debe articular, también, con las regulaciones vigentes para el desempeño profesional específico, con situaciones disímiles según cada país, como ya fue señalado.

El reconocimiento para el desempeño de actividades académicas tuvo un rápido avance ya que se firmaron dos protocolos: el de "Integración educativa para la prosecución de estudios de posgrado en las universidades de los países miembros del MERCOSUR", aprobado en la ciudad de Montevideo en noviembre de 1995 y el de "Admisión de títulos y grados universitarios para el ejercicio de actividades académicas en los países del MERCOSUR", aprobado en Asunción en junio de 1997. También, en noviembre de 1995, se aprobó el Protocolo de "Integración educativa para la formación de recursos humanos a nivel de posgrado", tendiendo a una formación comparable y equivalente y a la adaptación de los ya existentes en los países del MERCOSUR. En este Protocolo se establecen los criterios para definir los títulos de Posgrado (Especialización, Maestría y Doctorado), para la acreditación de los respectivos programas, tanto de orientación profesional como académica, y los referidos a la acreditación de posgrados interinstitucionales.

La situación más compleja y difícil se presentaba para el reconocimiento a fin de habilitar el desempeño profesional. En el ámbito de la Comisión Técnica Regional de Educación Superior (CTR-ES) se planteó, en primer lugar, un proceso basado en tablas de equivalencias, ya ensayado en convenios anteriores. Se acordó establecer grupos de trabajo por cada carrera de las que se seleccionaron inicialmente abogacía y contador público y, más tarde, ingeniería. Luego de las primeras reuniones de trabajo pudo comprobarse que este régimen era de muy difícil instrumentación.

En noviembre de 1996, en la XI Reunión de Ministros realizada en Gramado, Brasil, se resolvió dejar de lado el proceso basado en tablas de equivalencias y considerar la posibilidad de instrumentar un proceso basado en la acreditación de carreras de grado. Para ello se creó en junio de 1997 el Grupo de Traba- 
jo de Especialistas en Evaluación y Acreditación de la Educación Superior, encomendándosele la elaboración de una propuesta de organización de un sistema de acreditación de instituciones y carreras que permitiese facilitar el reconocimiento de títulos de grado.

En junio de 1998 los Ministros de Educación de los países del MERCOSUR y los de Chile y Bolivia, aprobaron un Memorando de Entendimiento para la Implementación de un Mecanismo Experimental para la Acreditación de Carreras de Grado. Este Memorando plantea los principios generales, los criterios para la determinación experimental de las carreras, los procedimientos para la acreditación y sus alcances e implicaciones.

\subsubsection{Normas del Mecanismo de Acreditación MERCOSUR (MEXA)}

El Memorando de Entendimiento, aprobado por la RME, planteó, entre otros, los siguientes puntos principales:

- Otorgar validez a los títulos de aquellas carreras que lo requieran para el ejercicio de la profesión;

- Adoptar un sistema de libre adhesión, periódico de aplicación gradual y experimental;

- Incluir un paso previo de autoevaluación;

- Proceso de evaluación por pares de acuerdo con los requisitos establecidos a nivel regional;

- Los requisitos se referirán a la carrera en su integridad (planes de estudio, cuerpo docente, la infraestructura y equipamiento, etc.);

- Los organismos de competencia a nivel nacional serán las "Agencias Nacionales de Acreditación;

- Se establece la creación de la "Reunión de Agencias de Acreditación del MERCOSUR" como instancia de monitoreo y cooperación regional.

Se estableció, asimismo, que el Mecanismo se aplicaría en forma experimental y gradual en carreras en que el título universitario sea requisito o condición para el ejercicio de la profesión aunque, con la aclaración, de que el reconocimiento académico del título "no conferirá de por sí el derecho al ejercicio de la profesión", para distinguir el proceso de acreditación de las regulaciones que se adopten en materia de desempeño profesional. Se determinó que el lapso máximo para la primera acreditación fuese de cinco años y se extendiese hasta 
que se lleve a cabo el segundo proceso si la solicitud para el nuevo plazo fuese presentada en tiempo y forma.

\subsubsection{Elaboración de los criterios e indicadores para la acreditación de las carreras}

El MEXA se desarrolló para las carreras de Medicina, Ingeniería y Agronomía, por lo que se constituyeron las respectivas comisiones consultivas de expertos con representantes de las universidades y asociaciones profesionales de cada uno de los países. Las coordinaciones de dichas comisiones fueron asumidas por especialistas de distintos países: la de Medicina fue coordinada por una brasileña, la de ingeniería por un argentino y la de agronomía por un uruguayo. La elaboración de los criterios generales y la coordinación técnica fueron asumidas por el GTEEA y por la CTR-ES.

Los documentos producidos posibilitaron orientaciones adecuadas para el desarrollo del MEXA y se constituyen en un excelente antecedente en cuanto a convergencia regional.

\subsubsection{Desarrollo y finalización del MEXA. El nuevo ARCU-SUR}

El MEXA ya ha concluido exitosamente el proceso de acreditaciones previstas con carácter experimental. Desde el año 2004 al año 2007 se han acreditado 19 carreras de Agronomía, 29 carreras de Ingeniería de 6 especialidades y 15 carreras de Medicina. Se cuenta con más de 180 pares capacitados en normas regionales.

Actualmente está poniéndose en marcha una nueva propuesta -ya de carácter definitivo- para instalar un proceso de acreditación de carreras de grado, a partir de las experiencias recogidas durante la implementación del Mecanismo Experimental: el ARCU-SUR.

En la reunión de Ministros de Educación, realizada en junio del 2008, se firmó un convenio internacional para la Creación e Implementación de un Sistema de Acreditación de Carreras Universitarias para el Reconocimiento Regional de la Calidad Académica de las respectivas Titulaciones en el MERCOSUR, lo que permitirá contar con un mecanismo permanente de Acreditación de Carreras del MERCOSUR. Este mecanismo se denomina ARCU -SUR.

En este marco, en la reunión de Ministros de Educación, realizada en junio del 2008, se estableció la firma de un convenio internacional del Memorandum de Entendimiento sobre la Creación e Implementación de un Sistema de Acreditación de Carreras Universitarias para el Reconocimiento Regional de la 
Calidad Académica de las respectivas Titulaciones en el MERCOSUR, lo que permitirá contar con un mecanismo permanente de Acreditación de Carreras del MERCOSUR. Este nuevo mecanismo se denomina ARCU -SUR.

3.1.4 El Sistema de Acreditación de Carreras Universitarias para el Reconocimiento Regional de la Calidad Académica de las respectivas Titulaciones en el MERCOSUR (ARCU-SUR)

Sus propósitos son los de:

- Promover la movilidad de personas entre los países de la región y apoyo a mecanismos regionales de reconocimiento de títulos o diplomas universitarios;

- Estimular el conocimiento recíproco, la movilidad y la cooperación solidaria entre las respectivas comunidades académico-profesionales de los países, elaborando criterios comunes de calidad en el ámbito del MERCOSUR;

- Programar la ejecución coordinada y solidaria de un programa de integración regional, la mejora permanente de la formación de recursos humanos.

Funciona con los siguientes principios generales:

- la acreditación certifica la calidad académica de las carreras de grado, estableciendo que satisfacen el perfil del egresado y los criterios de calidad previamente aprobados a nivel regional para cada titulación;

- el Sistema ARCU-SUR dará garantía pública en la región del nivel académico y científico de los cursos, que se definirá según criterios y perfiles tanto o más exigentes que los aplicados por los países en sus instancias nacionales análogas;

- el proceso de acreditación será continuo, con convocatorias periódicas, coordinadas por la Red de Agencias Nacionales de Acreditación (RANAs), la que establecerá las condiciones para la participación;

- que la participación será voluntaria;

- que el proceso de acreditación comprende la consideración del perfil del egresado y de los criterios regionales de calidad en una autoevaluación, una evaluación externa por comités de pares y una resolución de acreditación de responsabilidad de la Agencia Nacional de Acreditación;

- la acreditación tendrá vigencia por un plazo de seis años. 
La administración del ARCU-SUR se delegará a las Agencias Nacionales de Acreditación específicas, responsables de los procesos de evaluación y acreditación de la educación superior, designadas por el Estado Parte o Asociado ante la Reunión de Ministros de Educación.

Las Agencias Nacionales de Acreditación deben reunir los siguientes atributos:

a) Ser una institución de derecho público.

b) Ser dirigida por un órgano colegiado.

c) Dar garantía de su autonomía e imparcialidad, estar integrada por miembros y personal idóneos, y contar con procedimientos adecuados a las buenas prácticas internacionales.

Además, las Agencias Nacionales de Acreditación, quedarán organizadas como una Red, que se dará sus propias reglas de funcionamiento y adoptará decisiones por consenso.

Las pautas operativas de implementación son las siguientes:

- La evaluación para la acreditación comprenderá a la carrera integralmente.

- La acreditación requerirá un proceso de autoevaluación participativo.

- En el proceso de acreditación deberá requerirse el dictamen de un Comité de Pares.

- Los Comités serán designados por la correspondiente Agencia Nacional de Acreditación. El comité de pares debe incluir al menos dos representantes de distintos Estados Partes o Asociados al MERCOSUR, diferentes del país al que pertenece la carrera.

- Cada Agencia Nacional de Acreditación otorgará o denegará la acreditación y será registrada por la Red de Agencias Nacionales de Acreditación y publicada por la CRC-ES. La información y publicidad de las resoluciones deberán referirse solamente a las carreras acreditadas.

En cuanto a los alcances se establece que los Estados Partes del MERCOSUR y Estados Asociados, reconocen mutuamente la calidad académica de los títulos o diplomas de grado otorgados por Instituciones Universitarias, cuyas carreras hayan sido acreditadas y que el reconocimiento de la calidad académica de los títulos no confiere de por sí, derecho al ejercicio de la profesión en los demás países. 
La acreditación en el Sistema ARCU-SUR será impulsada por los Estados Partes del MERCOSUR y Estados Asociados, como criterio común para facilitar el reconocimiento mutuo de títulos o diplomas.

La acreditación de las carreras otorgada por el Sistema ARCU-SUR será tomada en cuenta por los Estados Partes y Asociados, como criterio común para articular con programas regionales de cooperación como vinculación, fomento, subsidio, movilidad entre otras, que beneficien a los sistemas de educación superior en su conjunto.

En cuanto a los criterios se considera el perfil de egreso en relación con la acreditación de formación equivalente para el reconocimiento regional.

Las dimensiones acordadas por Comisiones Consultivas de las titulaciones son: Contexto Institucional, Proyecto académico, Comunidad universitaria, Infraestructura.

La dimensión Contexto Institucional incorpora la información y el análisis sobre la universidad y la carrera en relación con ella.

En cuanto al cronograma, en septiembre del 2008 se realizó la Reunión de la Red de Agencias. En ella se acordó la realización de Talleres para Pares nacionales y regionales destinados a formar aproximadamente 90 pares internacionales para cada titulación.

Además se estableció el siguiente cronograma para las convocatorias:

- Agronomía y Arquitectura: agosto del año 2008

- Veterinaria y Enfermería: febrero del año 2009

- Ingenierías: septiembre del año 2009

- Medicina y Odontología: abril del año 2010

En cuanto a los avances alcanzados hasta ahora se puede señalar lo siguiente:

El Primer Ciclo de acreditación comprende siete titulaciones y cuatro convocatorias, comenzando por las carreras de Agronomía y Arquitectura. En dicha convocatoria se formalizaron 59 de Agronomía y 49 de Arquitectura entre los 7 países:

- Argentina: 8 carreras de Agronomía y 7 de Arquitectura

- Bolivia: 5 carreras de Agronomía y 5 de Arquitectura

- Brasil: 20 carreras de Agronomía y 20 de Arquitectura

- Chile: 9 carreras de Agronomía y 12 de Arquitectura

- Paraguay: 7 carreras de Agronomía y 12 de Arquitectura 
LA CONVERGENCIA DE LA EDUCACIÓN SUPERIOR EN

AMÉRICA LATINA Y SU ARTICULACIÓN CON LOS ESPACIOS

EUROPEO E IBEROAMERICANO. POSIBILIDADES Y LÍMITES

- Uruguay: 1 carrera de Agronomía y 3 de Arquitectura

- Venezuela: 9 carreras de Agronomía

\section{LOS PROGRAMAS Y ESTUDIOS DEL IESALC DE LA UNESCO}

El Instituto Internacional para la Educación Superior en América Latina y el Caribe (IESALC) de la UNESCO -con sede en Caracas, Venezuela- viene desarrollando desde hace más de una década una serie de trabajos y estudios nacionales y regionales sobre la educación superior que contribuyen fuertemente a la convergencia de los sistemas nacionales y a la articulación de sus políticas. Para ello puso en marcha, en el año 2001, el Observatorio de la Educación Superior en América Latina y el Caribe, con el que ha pretendido generar un ámbito de reflexión al mas alto nivel sobre la problemática universitaria y su transformación, abrir un espacio de sensibilización e intercambio de información digitalizada especializada, dar acceso regular al acervo de informaciones y datos de dominio público sobre educación superior y facilitar la socialización del conocimiento y la convergencia de los sistemas.

El IESALC ha generado una importante producción de estudios nacionales y regionales sobre educación superior, tanto en los aspectos generales como sobre aspectos específicos. En el caso de los estudios nacionales se han concluido alrededor de diez de ellos, en su mayoría ya editados; antes de su versión definitiva el IESALC ha organizado talleres nacionales para que autoridades educativas y universitarias y especialistas puedan brindar sus aportes al estudio elaborado por un especialista destacado del país. Estos estudios nacionales abarcan la evolución y el contexto histórico de la educación superior en cada país, su relación con el contexto nacional e internacional, la descripción detallada del sistema, el gobierno y la gestión, los actores de la educación superior (estudiantes, docentes, egresados, no docentes, etc.), las estructuras académicas vigentes de grado y posgrado, la educación a distancia, los procesos de evaluación y acreditación, la investigación científico-tecnológica, el financiamiento y los principales avances en materia de innovaciones y reformas. Estos trabajos constituyen una buena base para promover estrategias de convergencia y articulación entre los países de América Latina.

Además de estos estudios nacionales, el IESALC ha promovido la realización de estudios por países sobre otros temas que permiten una mayor profundización del conocimiento sobre la educación superior en la Región. La mayor parte de estos estudios están disponibles en Internet. Para cada tema el IESALC ha promovido la elaboración de un estudio comparativo regional, que se discute en 
un seminario regional específico. Las temáticas abarcadas por el IESALC son las siguientes: evaluación y acreditación de la calidad, reformas en la educación superior, legislación vigente y su evolución, internacionalización y nuevos proveedores y modalidades, universidades indígenas, universidades religiosas, macro-universidades y universidades pedagógicas. También ha realizado estudios que profundizan otros temas como los del género en la educación superior.

En los años 2007 y 2008 ha promovido la realización de estudios y trabajos tendientes a la organización de la Conferencia Regional de Educación Superior de la UNESCO (CRES-2008), llevada a cabo en Cartagena de Indias, Colombia, en junio de 2008, con participación de más de 3500 autoridades universitarias y especialistas de América Latina y el Caribe. La Declaración Final de la misma brinda las bases para una estrategia latinoamericana en materia de educación superior de carácter integrador. Tanto esta Declaración como el conjunto de trabajos presentados en la CRES han constituido un aporte significativo para la Conferencia Mundial de Educación Superior de la UNESCO, realizada en París, en julio de 2009.

Entre los trabajos elaborados para la CRES se pueden destacar los siguientes, que pueden ser consultados en la página WEB del IESALC (www.iesalc. unesco.org.ve) :

- el Mapa Comparativo de la Educación Superior en América Latina y el Caribe, con una detallada y muy útil descripción y análisis de las instituciones y sistemas de educación superior;

- el Glosario de la Educación Superior en América Latina y el Caribe, cuya versión final ha estado a cargo del autor de este trabajo;

- el libro sobre Tendencias de la Educación Superior en América Latina, que contiene diez importantes trabajos sobre el tema;

- el Proyecto sobre Pensamiento Universitario en América Latina ha editado su primer libro -Pensadores y Forjadores de la Universidad Latinoamericana- y continuará con otros estudios de carácter histórico-político;

- el proyecto sobre Acreditación y Evaluación ha llevado a cabo un estudio sobre los sistemas de evaluación y certificación de los postgrados en la región - con participación de CAPES de Brasil, de la CONEAU de Argentina y de la Red RIACES-, trabajos que posibilitarán avanzar en cuanto a una mayor convergencia en materia de postgrados; este proyecto también incluye un Curso Virtual sobre Evaluación y Acreditación de la Calidad de la Educación Superior, tanto en sus aspectos conceptuales como en los metodológicos, elaborado para el IESALC por la Universidad Nacional de 
Tres de Febrero, bajo la dirección del autor de este trabajo, el que actualmente está siendo actualizado para su relanzamiento. En el marco de este proyecto el IESALC ha publicado el libro "Hacia una Política Regional de Aseguramiento de la Calidad en Educación Superior para América latina y el Caribe", con trabajos sobre los procesos de evaluación y acreditación, con énfasis en los de postgrado, la educación transfronteriza y el mejoramiento de la calidad.

El IESALC ha publicado, asimismo, en el año 2006, un libro que contiene una síntesis de sus principales trabajos y estudios -acompañado por un $\mathrm{CD}$ que incluye 302 estudios sobre educación superior en la región- con el título: "Informe sobre la Educación Superior en América Latina y el Caribe 20002005. La metamorfosis de la educación superior".

Como ya se ha señalado el IESALC ha promovido la consolidación de ENLACES, una red que agrupa a las redes ya existentes, con el objetivo de contribuir a la convergencia de la educación superior en América Latina y el Caribe y trabajar para la construcción de un Espacio Común para toda la región.

Por todo ello, se puede afirmar que la tarea del IESALC en la última década se ha constituido en un aporte muy importante para el desarrollo de estrategias de convergencia y articulación de la educación superior en la región.

\section{LOS TRABAJOS Y PROYECTOS DE OTROS ORGANISMOS Y REDES}

\subsection{Los de la OEI}

La Organización de Estados Americanos para la Educación, la Ciencia y la Cultura (OEI) también desarrolla una tarea contributiva a la convergencia y articulación entre los sistemas educativos y en la educación superior del Espacio Iberoamericano. La Revista Iberoamericana de Educación, las colecciones de libros -en especial Cuadernos de Iberoamérica y la serie "Educación Comparada" de Cuadernos de la OEI- y otras publicaciones y trabajos facilitan el conocimiento mutuo en los países y sus sistemas educativos favoreciendo el desarrollo de políticas y proyectos compartidos.

En el ámbito de la educación superior, la OEI está promoviendo estrategias de cooperación ínteruniversitaria entre los países de la región, las que van contribuyendo en forma paulatina a su articulación. Entre los programas que desarrolla se puede mencionar al PIMA (Proyecto de Intercambio y Movilidad 
Académica), que consiste en el intercambio de estudiantes de universidades de la región iberoamericana en una cada vez mayor número de áreas. Como lo ha demostrado la experiencia europea, el intercambio de estudiantes es una estrategia muy eficiente para promover los procesos de integración regional y la convergencia de los sistemas de educación superior y la articulación entre las instituciones universitarias, como es el caso del programa Sócrates-Erasmus.

El PIMA -iniciado por al OEI en 1999- es un programa multilateral organizado en redes temáticas con participación de universidades españolas, portuguesas y latinoamericanas. Está dirigido a estudiantes de grado (pregrado para otros países) y se basa en los siguientes puntos: la significación de la movilidad de estudiantes, el trabajo en red, la focalización en áreas temáticas y el reconocimiento de los estudios.

Recientemente ha organizado un Centro de Altos Estudios Universitarios y ha puesto en marcha-conjuntamente con la Secretaría General Iberoamericana (SEGIB)- la Iniciativa Iberoamericana de Movilidad Académica de Posgrado "Pablo Neruda". Ambos proyectos contribuirán a la estrategia de la Convergencia Iberoamericana.

\subsection{Los programas y acciones de la Organización Universitaria Interamericana (OUI)}

La OUI fue fundada en 1979 en Québec, Canadá, donde está su Sede. Es una organización internacional dedicada a la cooperación entre las instituciones universitarias y al desarrollo y articulación de la educación superior en toda América, desde Canadá en el norte hasta Argentina y Chile en el sur. Está integrada por más de 400 miembros: universidades públicas y privadas, centros de investigación, asociaciones universitarias nacionales o regionales, consejos de rectores, etc.

Sus actividades son llevadas a cabo a través del Instituto de Gestión y Liderazgo Universitario (IGLU) y del Colegio de las Américas (COLAM) Las acciones de ambos organismos han sido fuertemente contributivas para los procesos de convergencia y articulación de la educación superior en América Latina, en especial a través de sus cursos y otras actividades de formación y cooperación.

El IGLU ha capacitado desde su fundación en 1983 alrededor de 1500 dirigentes universitarios, a través de sus cursos de carácter subregional. Entre los objetivos de los cursos IGLU están -además de los de capacitación para el liderazgo y la capacitación en gestión universitaria- los de favorecer los 
intercambios entre los participantes de diversos países e instituciones, los de promover los estudios comparados, los de difundir los resultados de estudios e investigaciones llevados a cabo en las tres Américas y en Europa, etc.

Además de estos cursos, el IGLU organiza seminarios y talleres sobre temas específicos, tanto por propia iniciativa como a propuesta de universidades miembros. En estas actividades se profundizan tanto los aspectos de carácter político y estratégico como los vinculados con lo metodológico de la gestión institucional, académica y administrativa.

El Colegio de las Américas (COLAM) fue creado en 1997 y sus actividades se refieren a aspectos vinculados con la cooperación universitaria sobre temas de interés hemisférico y de integración continental, favoreciendo la comprensión intercultural, el uso pedagógico de las nuevas TIC, la interdisciplinariedad y las relaciones interamericanas.

Las desarrolla a través de los denominados Seminarios Interamérica destinados a estudiantes de diversos países y disciplinas y de Redes Interamericanas de Formación, (RIF) Actualmente funcionan alrededor de diez redes sobre temáticas muy diversas y de interés continental.

La acción de la OUI está orientada actualmente por el Plan de Acción 2006-2010, que se propone desarrollar acciones de asesoría de modernización hemisférica en materia de gestión universitaria, de promoción continental de la excelencia académica y de movilidad interuniversitaria y de animación de redes académicas, entre otras. En la actualidad está promoviendo la articulación con universidades de la región con el objeto de fortalecer la formación de sus directivos en materia de gestión universitaria.

\subsection{Los de otros programas y redes}

\subsubsection{La Red Iberoamericana para la Acreditación de la Calidad de la Educación Superior (RIACES)}

Esta Red fue constituida en mayo de 2003 por las agencias de evaluación y acreditación de la calidad de diversos países de América Latina y la ANECA de España y por ministerios de educación de la región, con el apoyo de organismos internacionales, como la OEI, Sus objetivos son contributivos a la convergencia y articulación de la educación superior en el espacio iberoamericano ya que se propone el desarrollo de proyectos y acciones de intercambio, conocimiento mutuo y trabajo conjunto.

La Red está organizada por comisiones de trabajo sobre temas específicos: Estudios Comparados; Gestión y mantenimiento de un Portal propio (www. 
riaces.org); Diseño de un software para Autoevaluación; Talleres de Formación para Evaluadores; Glosario de términos de evaluación y acreditación; Buenas prácticas en evaluación y acreditación; Estudio comparativo de títulos.

\subsubsection{Los Programas ALFA de la Comisión Europea}

Estos programas se han constituido en los últimos años en instrumentos muy significativos para la articulación y convergencia en materia de educación entre los países de la Comisión Europea y los de América Latina.

Los proyectos ALFA (América Latina-Formación Académica) son propuestas de trabajo en red entre instituciones universitarias europeas y latinoamericanas. Estas redes temáticas están constituidas, por lo menos, por seis universidades de países diferentes: tres europeos y tres de los dieciocho países de América Latina, coordinadas por una de ellas.

Desde el año 2000 se han llevado a cabo múltiples rondas, en las que se han aprobado más de 300 proyectos. El análisis de los proyectos aprobados -ya ejecutados o en ejecución- muestra una muy interesante diversidad temática, de instituciones coordinadoras y de países y universidades participantes. Estas redes han producido una muy valiosa documentación, a la que puede accederse a través de las respectivas páginas WEB y de trabajos editados. La nómina completa de proyectos y una síntesis de los mismos puede consultarse en http://europa.eu.int/comm/europeaid/proyects/alfa/information/ compendium.es.pdf

Entre los proyectos desarrollados puede señalarse el de Acreditación y Reconocimientos Oficiales entre Universidades del MERCOSUR y la UE (ACRO), iniciado en febrero de 2002 y finalizado en el año 2005. Sus objetivos fueron los de desarrollar marcos conceptuales de la acreditación en el contexto europeo y latinoamericano (especialmente en el MERCOSUR), establecer criterios comunes para el reconocimiento de títulos entre las universidades participantes y proponer el establecimiento de mecanismos estables y generalizables a otras universidades de ambas regiones para la acreditación y el reconocimiento de títulos. El Proyecto ACRO fue coordinado por la Universidad de Valencia a través de José-Ginés Mora e integrado por universidades de España, Holanda, Italia, Portugal, Argentina, Brasil y Uruguay. Ha producido una importante documentación sobre los procesos de evaluación y acreditación en la educación superior en Europa y en América Latina y en cada uno de los países integrantes (http://www.uv.es/alfa-acro) Este Proyecto tuvo como actividad de cierre la realización del Congreso Internacional "América Latina y Europa, ante los procesos de convergencia de la Educación Superior", llevado a cabo 
en la Universidad Nacional de Tres de Febrero - Coordinadora para América Latina del Proyecto ACRO-, Buenos Aires, Argentina, en el mes de junio de 2004. En dicho Congreso participaron más de 400 especialistas de países latinoamericanos -en especial de Argentina y de otros países del MERCOSUR-y de Europa y se presentaron alrededor de veinte importantes ponencias. Sus conclusiones constituyen un aporte decisivo para la consolidación de un Espacio Latinoamericano de Educación Superior y para su convergencia con el Europeo.

Otros proyectos muy significativos para la convergencia regional han sido el Túnning-América Latina y el denominado 6 x 4. Los documentos y trabajos producidos por ambos deberán ser tenidos en cuenta por las universidades y autoridades al encararse los procesos de convergencia y articulación de la educación superior latinoamericana y su articulación con el EEES.

Durante el año 2008, la Comisión Europea hizo una nueva convocatoria -denominada ALFA III-. Uno de los presentados-coordinado por el autor de este artículo- ha sido el Proyecto Convergencia, constituido por una importante red de 62 universidades: 46 de 18 países de América Latina y 16 de 7 países europeos, el que no fue aprobado por la CE.

\subsubsection{Proyectos ALFA Tünning Europa y Tünning América Latina}

El proyecto Tünning es un proyecto europeo que comenzó en el año 2000 ligado directamente a los objetivos políticos del proceso de Bolonia y posteriormente a las estrategias de la Reunión de Lisboa. Sus coordinadores fueron la Universidad de Deusto (España) y la Rijksuniversiteit Groningen (Holanda).

El objetivo del proyecto ha sido el de contribuir significativamente a elaborar una marco de calificaciones y títulos comparables y compatibles. Estas calificaciones y títulos deberían ser descriptos en términos de carga de trabajo, niveles, resultados de aprendizajes, competencias y perfiles. El proyecto fue desarrollando modelos para el rediseño, el desarrollo, la implementación de títulos en el marco del Proceso de Bolonia, y la mejora y evaluación de su calidad.

El principal paso del proyecto fue identificar conceptualmente el término competencia como núcleo principal de los resultados de aprendizaje que un estudiante debería adquirir , desarrollar o demostrar a partir de un módulo, un curso o de un programa de primer, segundo o tercer ciclo. Estos resultados de aprendizaje estarían asociados al reconocimiento de los créditos de cada estudiante. Las competencias, desde esta perspectiva deberían ser una combinación dinámica de conocimiento, comprensión, destrezas y habilidades. El proyecto Tünning se planteó desarrollar las siguientes pasos: 
a. Identificar competencias genéricas, académicamente generales, para cada ciclo. Se identificaron treinta competencias clasificadas en tres tipos: instrumentales, interpersonales y sistémicas;

b. Identificar competencias específicas para cada temática o área disciplinar;

c. Discutir el rol del Sistema Europeo de Créditos Transferibles (ECTS);

d. Discutir estrategias de aprendizaje, de enseñanza y de evaluación;

e. Discutir el rol de la mejora de la calidad dentro del proceso educativo (enfatizando sistemas basado en la cultura interna de las instituciones).

El proyecto avanzó claramente en la identificación de competencias genéricas y específicas, ya que se constituyeron nueve grupos temáticos (Administración y Negocios, Química, Ciencias de la Educación, Estudios Europeos, Historia, Geología, Matemática, Enfermería y Física). Fue, junto a otras iniciativas oficiales, como los Descriptores de Dublin (Dublin descriptors, Joint Quality Initiative - http://www.jointquality.nl/), uno de los referentes dentro del mundo académico europeo de estrategias para poder adecuar los estudios universitarios al EEES.

Sin embargo, como en el resto de las iniciativas, fue más difícil llegar a acuerdos o establecerse como marco de referencia en iniciativas de evaluación de la calidad. Específicamente el problema de asociar la calidad al desarrollo y evaluación de las competencias (que, por definición, deben ser demostrables) implica reducir la concepción de la calidad a resultados de aprendizaje de los estudiantes, obviando las tendencias actuales de evaluación de la calidad que consideran fundamental analizar dimensiones relacionadas con los procesos. Otro de los aspectos críticos es la reducción de la calidad universitaria a indicadores demostrables empíricamente en un momento dado de desarrollo de competencias.

Basado en la experiencia europea, el proyecto ALFA Tünning América Latina, también coordinado por las universidades de Deusto y Gronningen, buscó trasladar la idea de convergencia de la educación superior al ámbito de América Latina. El núcleo fundamental del proyecto ha sido el de promover titulaciones comparables y comprensibles a lo largo de los sistemas de educación superior de América Latina, a partir de la identificación de competencias genéricas y específicas, como en el proyecto original europeo.

Entre los objetivos propuestos, además de buscar la convergencia de títulos en América Latina, se dejó de lado la preocupación por el desarrollo de sistemas 
de créditos y la evaluación de la calidad, y se centró en necesidades propias de la región como el establecimiento de redes y puentes entre universidades, y el desarrollo compartido de currículos (esta palabra aparece en el léxico del nuevo proyecto latinoamericano pero no se encuentra en el original). Se identificaron 27 competencias genéricas y posteriormente se desarrollaron las competencias específicas en 12 áreas disciplinares: Administración de Empresas, Arquitectura, Derecho, Educación, Enfermería, Física, Geología, Historia, Ingeniería Civil, Matemáticas, Medicina y Química.

En el caso del proyecto europeo se pudo trabajar más fácilmente en la articulación de competencias genéricas y específicas por ciclos. ya que todos los sistemas debían confluir hacia un sistema similar de ciclos de grado y de posgrado. En América Latina, al no tener la obligación de converger, esto ha sido más difícil, ya que los títulos están definidos en otros términos . A su vez, el concepto de competencia no es del todo aceptado en la región, por lo que el proyecto dedicó bastante tiempo en instalar el concepto.

Esto implicó un límite al intento de incorporar a América Latina la estrategia de Bolonia. Principalmente porque en el proyecto europeo primero había existido la voluntad de los gobiernos de asumir un compromiso con la convergencia en Educación Superior -el EEES- y el proyecto Tünning comenzó a trabajar sobre los acuerdos básicos a los que se había llegado. Esto permitió profundizar a partir de necesidades propias de las universidades europeas (adaptar las titulaciones). Sin embargo, en América Latina esto no fue así a pesar que este proyecto involucró a un alto número de universidades : 181.

\subsubsection{El proyecto ALFA 6x4 UEALC}

Otro de los proyectos ALFA que se preocupó por la integración y la convergencia de los sistemas de educación superior en América Latina es el Proyecto 6X4. Propuestas y acciones para la transformación de la Educación Superior en América Latina. El 6x4 se constituyó con la necesidad de contribuir al desarrollo y utilización de un sistema común para la acumulación y transferencia de créditos académicos para las instituciones de educación superior de América Latina y el Caribe (SICA-ALC), basado en el volumen total de trabajo que requiere un estudiante medio para lograr las competencias profesionales en el nivel licenciatura o su equivalente.

El acrónimo provino del diseño de la estructura de trabajo del proyecto: se conformaron 6 grupos de trabajo según áreas disciplinar/profesional (Administración, Ingeniería Electrónica, Medicina, Química, Historia y Ma- 
temáticas), a partir de 4 ejes de análisis: competencias profesionales, créditos académicos, evaluación y acreditación y formación para la innovación y la investigación.

Desde el inicio del proyecto se identificaron dos aspectos claves: primero, que aunque había algunas experiencias en América Latina y el Caribe, los sistemas de créditos estaban más desarrollados en Estados Unidos y en Europa y se debería aprender de dichas experiencias; y segundo, que la formulación de un Sistema de Créditos debería surgir desde la autonomía y la responsabilidad de las instituciones de educación superior de América Latina. A su vez se entendió al crédito como una unidad de medida del esfuerzo que necesita un estudiante medio para adquirir alguna competencia. Este sistema implicaba cuatro distintos niveles de flexibilidad: pedagógica, curricular, de la estructura académica y la gestión académica de las instituciones.

Se avanzó en la elaboración de un Sistema de Créditos Académicos (SICA), basados en competencias generales y específicas. El SICA se concibió como un modelo que permitiera valorar y comparar resultados de aprendizajes de distintas instituciones, distintos programas y distintos contextos, en un marco donde se generalizan estas practicas a nivel internacional. El criterio de equivalencia común reconoce al crédito como el trabajo de un estudiante durante 32 horas (en el ETCS es de entre 25 y 30 horas).

Se desarrolló también un Complemento al Título (CAT), similar al Suplemento al Diploma del EEES (SD). La diferencia de uno con el otro es que el CAT implica una descripción más densa del contexto donde se produjeron los aprendizajes, propio de la complejidad del sistema en América Latina.

No se pudo avanzar sustantivamente en los tercer y cuarto ejes temáticos: Evaluación y acreditación y Formación para la innovación y la investigación. En relación con la evaluación, en algunas áreas se propuso la posibilidad de aplicar un examen final de graduación, lo que implicaría un desconocimiento parcial de los créditos asumidos por los estudiantes durante la carrera.

\subsection{Redes de universidades}

En las últimas décadas se han ido constituyendo diversas redes de universidades, tanto entre instituciones de América Latina como entre éstas y universidades europeas. Estas redes son un factor contributivo al trabajo en común entre instituciones de ambas regiones y de diversos países, por lo que favorecen los procesos de articulación y convergencia en materia de educación superior pero, a su vez, evidencian síntomas de fragmentación que deben ser superados. 
Una de ellas es Columbus, -con sede en París- una asociación de 64 universidades europeas y latinoamericanas creada en 1987, que promueve la constitución de redes de instituciones universitarias que actúan conjuntamente y que ofrece servicios de formación, evaluación, auditoria y consultoría a universidades y a gobiernos. Su actual programa de trabajo incluye proyectos de convergencia de los sistemas de educación superior, sobre nuevas TIC, internacionalización de la educación superior, educación contínua, evaluación de las ingenierías, etc. (www.columbus-web.com.es).

La Unión de Universidades de América Latina (UDUAL), creada en el año 1959, funciona con sede en México DF y está integrada por 169 universidades de toda América Latina. Desarrolla una importante actividad académica de intercambio y de integración regional. Su revista Universidades se constituye en un importante órgano para la difusión de estudio y artículos sobre la educación superior latinoamericana. También edita su Colección UDUAL de libros sobre temas universitarios e Idea Latinoamericana, constituídas con libros sobre aspectos históricos, filosóficos y culturales de la región. Sus principales documentos y trabajos pueden ser consultados en su página web (www.udual.org).

La Asociación de Universidades del Grupo Montevideo fue creada en 1991 y está integrada por universidades públicas y autónomas de Argentina, Brasil, Chile, Uruguay y Paraguay. Entre sus objetivos están los de desarrollar conjuntamente una masa crítica de alto nivel entre sus miembros, promover la investigación científica y tecnológica y la formación continua, mejorar las estructuras de gestión de las universidades que la integran y fomentar la interacción entre las instituciones miembros. En su seno funcionan cinco Cátedras UNESCO sobre Cultura de la Paz, sobre Libertad de Expresión, sobre derechos Humanos, sobre Nuevas técnicas de Enseñanza e Innovación Pedagógica en la Educación Superior y sobre Microelectrónica. En su ámbito funcionan diez comités Académicos sobre distintos temas científico-tecnológicos.

En su página WEB (www.grupo_montevideo.edu.uy) se informa sobre las múltiples actividades académicas desarrolladas desde el año 1991.

En Centroamérica, en 1948, se creó el Consejo Superior Universitario Centroamericano (CSUCA), organismo precursor de la integración subregional y del funcionamiento de redes interuniversitarias. En sus seis décadas de existencia al CSUCA ha tenido etapas muy significativas en cuanto a promover la integración universitaria en la región y a contribuir a su mejoramiento. Sus publicaciones y trabajos han sido muchas veces de gran importancia tanto en Centroamérica como en el conjunto de América Latina. Actualmente funciona en el marco del Sistema de Integración Centroamericano (SICA). 
El CSUCA está integrado actualmente por dieciséis universidades públicas de Centroamérica y Panamá (www.csuca.edu.gt) Ha creado el Sistema Centroamericano de Evaluación y Acreditación de la Educación Superior (SICEVAES) que, conjuntamente al MEXA del MERCOSUR, se constituyen en los dos mecanismos subregionales de mayor significación en materia de aseguramiento y acreditación de la calidad de la educación superior en América Latina.

El CSUCA cuenta, también, con el Consejo Regional de Vida Estudiantil (CONREVE) y con una Red de Sistemas de Información Documental de Universidades Centroamericanas (Red SIID), que garantiza la interconexión telemática de los 16 sistemas de información documental de las universidades miembros. Tanto el SICEVAES como estos dos programas contribuyen eficazmente a la convergencia y articulación de los sistemas universitarios de Centroamérica y Panamá.

En la década del 70 se creó con sede en Santiago de Chile el Centro Interuniversitario de Desarrollo (CINDA), integrado actualmente por veintiocho universidades latinoamericanas y tres europeas (de España y de Italia) Sus objetivos son los de articular esta red de universidades con el desarrollo regional y de cada uno de los países. Ha llevado a cabo numerosos estudios y trabajos de consultoría y asesoramiento vinculados con el mejoramiento de la gestión y la calidad en la educación superior (www.cinda.cl).

En el año 1997 se creó en Buenos Aires, Argentina, la Red Latinoamericana de Cooperación Universitaria integrada por universidades de 14 países latinoamericanos. Esta Red promueve la integración regional, la cooperación y la excelencia académica y la generación y la difusión del pensamiento en América Latina. Sus principales áreas de trabajo están concentradas en la organización y gestión universitaria, la movilidad y la homologación de estudios, la acreditación institucional y por programas y las nuevas tecnologías para la educación superior.

Con objetivos similares en 1993 se creó la Asociación de Universidades de América Latina y del Caribe para la Integración www.aualcpi.org) Esta Asociación está integrada por universidades de veinte países latinoamericanos y promueve acciones de intercambio e integración en materia universitaria entre sus miembros bajo el lema "La comunidad latinoamericana de naciones es el nuevo lema de la integración".

Existen, también, otras redes interuniversitarias como la Asociación ORION, integrada por 40 universidades de países de América Latina, el Caribe y Europa; esta Asociación está iniciando el desarrollo del proyecto VALUE, financiado por la Unión Europea, destinado a la implementación del Espacio 
LA CONVERGENCIA DE LA EDUCACIÓN SUPERIOR EN

AMÉRICA LATINA Y SU ARTICULACIÓN CON LOS ESPACIOS

EUROPEO E IBEROAMERICANO. POSIBILIDADES Y LÍMITES

Común de Educación Superior, América Latina, Caribe y Unión Europea (ALCUE) (ver www.aorion,org.ar) Otra red es la de la Asociación de Universidades Amazónicas, creada en 1987, e integrada por 72 universidades de los 8 países amazónicos (www.unamaz.org). También funciona otra Red CRISCOS, con universidades de la sub región centro-oeste (andina) de Sudamérica.

\section{HACIA LA CONSTRUCCIÓN DEL ESPACIO LATINOAMERICANO DE EDUCACIÓN SUPERIOR Y SU ARTICULACIÓN CON EL IBEROAMERICANO Y EL EUROPEO. POSIBILIDADES Y PELIGROS}

En el marco de una situación similar de falta de convergencia -quizás agudizada por la trayectoria de siglos de sus sistemas universitarios- desde 1999 Europa está construyendo el Espacio Europeo de Educación Superior (EEES), denominado Proceso de Bolonia. En Bolonia, en junio de 1999, 29 ministros de educación europeos se comprometieron a: adoptar un marco de referencia común -transparente y flexible- para los cursos y los títulos de la educación superior; generalizar un sistema europeo de créditos transferibles y adoptar medidas para mejorar la calidad a través de la evaluación de los cursos y las instituciones. A partir de este inicio se han desarrollado un conjunto de políticas y acciones a nivel de gobiernos y de universidades que han impactado profundamente a los sistemas nacionales de educación superior, en el contexto de un amplio proceso de convergencia, que está implicando asegurar la comparabilidad, la compatibilidad, la transferencia y la flexibilidad en la educación superior europea para construir un sistema articulado e integrado.

Actualmente están comprometidos y avanzando con este proceso 46 países, muchos más que los que integran la ampliada Unión Europea. Ya hay una estructura común con Licenciatura -o Grado- de tres años (cuatro en España), Maestría de dos y Doctorado de otros tres (en total 8 años); un Sistema Europeo de Créditos Transferibles (ECTS), con validez gradual en todas las universidades europeas: y un sistema de aseguramiento de la calidad, con un ente regulador: el ENQA (European Net for Quality Accreditation), una amplia movilidad estudiantil y docente y múltiples redes de investigación y docencia que están sentando las bases del Espacio Europeo de la Educación Superior.

Europa ha promovido la construcción de un espacio común de la educación superior entre ambas regiones. La Cumbre de Presidentes de la Unión Europea y de América Latina y el Caribe formalmente ha creado el Espacio Común de Educación Superior ALCUE y ha ido aprobando diversas resoluciones, hasta 
ahora de escasa resonancia efectiva en la dinámica universitaria. Por su parte la Cumbre de Iberoamérica ha creado, también, el Espacio Iberoamericano de Educación Superior y el Espacio Iberoamericano del Conocimiento en el que ya se han hecho algunos avances. La puesta en marcha de la Secretaría General Iberoamericana (SEGIB) como brazo ejecutor de las Cumbres de Presidentes, propende también a la construcción de ese espacio común de la educación superior entre los países de ambas regiones. Alemania, Francia, Suecia, España, Portugal, e Italia, así como otras naciones europeas, también han propendido a construir redes y lazos entre los sistemas de educación superior a ambos lados del océano. La labor que desarrolla la OEI -el organismo para la región iberoamericana en materia de educación, cultura y ciencia- ya ha sido reseñada en el punto 5.1 y tiende a contribuir a la consolidación de estos espacios.

Sin embargo, las diversas iniciativas - tanto la ALCUE como la Iberoamericana- han tenido impactos aislados y no continuos, fragmentando y disgregando los espacios compartidos entre ambas regiones, al no afincarse, en primera instancia, en la necesidad de construir un espacio común de la educación superior en América Latina.

Frente a los avances del Espacio Europeo y del Iberoamericano y sus posibles convergencias con América Latina, se hace necesario trabajar hacia la convergencia de la educación superior en América Latina y en la construcción conjunta de un Espacio Común Latinoamericano, como requisito básico sobre el cual ir articulando -global y sectorialmente- el fortalecimiento efectivo del Espacio ALCUE y del Iberoamericano.

Los posibles avances de ambos espacios pueden constituirse en factores de mayor fragmentación de la educación superior latinoamericana, como ya está ocurriendo con la aplicación en varios países del modelo de diseño de planes de estudio por competencias -según el modelo del Proceso de Bolonia o la creación de sistemas de créditos, tomando el modelo del Europeo (ECTS). Por ejemplo, el Consejo de Rectores de la Universidades Chilenas (CRUCH) -que agrupa a sólo algunas de las universidades de ese país- ha creado un sistema de créditos universitarios sólo para las universidades que lo integran, aplicando el modelo del ECTS, lo que podría conducir a una mayor fragmentación académica tanto en Chile como en resto de América Latina.

Las estrategias de marketing de las universidades españolas -en general, para atraer mayor cantidad de estudiantes provenientes de América Latina ante la marcada disminución de estudiantes españoles por las bajas tasas de natalidad- son también un factor de fragmentación y de posible implantación de un peligroso proceso de carácter neo-colonial, que podría generar a una 
mayor fragmentación. Asimismo, hay que tener en cuenta que España integra plenamente el EEES (Proceso de Bolonia), por lo que le es difícil participar simultáneamente en el Espacio Europeo y en el denominado Iberoamericano. Por otra parte, hay que tener en cuenta que la influencia de la universidad española no ha sido siempre positiva en la historia de la universidad latinoamericana, por haberse constituido en muchos períodos en un factor retardatario, frente a avances importantes en América Latina, como lo ha sido la universidad autónoma, democrática, científica, participativa y progresista, nacida en la primeras décadas del siglo XX, a partir del Movimiento de la Reforma Universitaria de 1918. Europa y España están todavía muy lejos de este tipo de políticas universitarias progresistas.

En la actualidad, como ya se ha señalado, a pesar de los avances recién señalados de la educación superior en América Latina, ahora lamentablemente presenta un escenario de fuerte segmentación institucional; con diversidad y superposición de modelos organizativos y académicos; con desarticulación a nivel de cada país; con una creciente incidencia en muchos países de la educación trasnacional que, por su casi nulo control, genera fuertes resistencias en la comunidad académica; distintos marcos de regulación o apertura; con una fuerte tendencia a la privatización de los servicios ofrecidos, que alcanzan alrededor del $60 \%$ de la cobertura; con niveles muy diferenciados de calidad, etc, todo lo cual afecta y restringe las posibilidades de la convergencia regional. A su vez, como se ha señalado, existen numerosas redes de universidades que tienden a fragmentar aún más el escenario de la educación superior en la región por cuanto carecen de un sustrato común de estándares de funcionamiento de la educación superior en región. Lamentablemente las pocas iniciativas orientadas a la creación de un espacio latinoamericano de la educación superior, al producirse con formas aisladas y focalizadas en nichos y campos muy específicos de la educación superior y sin marcos de regulación comunes, tiende a disgregar y diferenciar aún más los sistemas nacionales de educación superior en la región y, por ende, dificultar en mayor medida la convergencia con el Espacio Europeo y con el Iberoamericano. Estos procesos (ALCUE e Iberoamericano) deberían contribuir y constituirse en factores favorables a la creación del espacio latinoamericano, a partir del cual se puedan organizar el ALCUE y el Iberoamericano de Educación Superior y del Conocimiento.

Por eso se constituye en un importante desafío trabajar fuertemente y con alta prioridad en un proceso de convergencia de la Educación Superior de América Latina, tanto en temas globales de la educación superior como en los sectoriales. Así, es necesario considerar la estructura académica, con el grado y el postgra- 
do y la investigación; la educación a distancia; las estructuras organizativas y los procesos de aprendizaje; los procesos de evaluación y acreditación; y las estructuras de créditos y reconocimientos académicos, etc. También hay que valorar los avances del MERCOSUR en materia universitaria, ya reseñados; en Centroamérica, los -entre otros- del Consejo Centroamericano de Acreditación y los de CSUCA; en la Comunidad Andina de Naciones, el Convenio Andrés Bello con el reconocimiento de los doctorados, así como diversos programas y proyectos facilitadores de la integración. También son muy importantes para tener en cuenta los llevados a cabo a través de organismos internacionales, particularmente por el IESALC de la UNESCO y la Organización Universitaria Interamericana y su IGLU, etc.

Además existen, como ya ha sido señalado, diversas organizaciones ínter universitarias con bastante actividad, algunas con larga trayectoria, lo que ya ha sido reseñado; todas ellas han puesto en marcha procesos de convergencia en diversos niveles, países, temáticas, etc, por lo que se hace necesario analizar sus simetrías y su convergencia así como sus contradicciones, en el marco de una dinámica que propenda a hacer confluir todas estas iniciativas.

La tradicional autonomía de las universidades en casi todos los países de la región -característica propia y específica de la educación superior pública en América Latina- aconseja que la estrategia para la construcción de la necesaria convergencia parta de las propias instituciones universitarias y de los diversos consejos y asociaciones de rectores y de universidades, públicos, privados o integrados, según sean los casos. A este proceso de convergencia deberán sumarse, asimismo, los Ministerios de Educación, las Cancillerías, los Organismos Internacionales, las agencias de evaluación y acreditación, así como los centros de altos estudios y de investigación y todos las organizaciones académicas, sociales, de profesores y de estudiantes que lo faciliten.

En Europa, el Espacio Europeo de Educación Superior se construyó como una iniciativa de los ministros de educación; es decir, de arriba para abajo, estrategia propicia en el marco de las características de los sistemas universitarios europeos. En América Latina debería construirse con el consenso entre todos los actores institucionales, pero donde el protagonismo fundamental debe provenir de las universidades y de sus principales actores.; es decir de abajo para arriba.

La construcción de estos procesos de convergencia debería llevarse a cabo en diversos ámbitos y mediante acuerdos, redes, acciones subregionales y regionales y a través de los diversos ejes problemáticos, a partir de los cuales podrá avanzarse hacia el establecimiento, entre todos, tanto de espacios regionales temáticos específicos como de un Espacio Común Latinoamericano de Edu- 
cación Superior, tomando como referencia los procesos de globalización de la educación superior y las experiencias y referencias del Proceso de Bolonia. En la creación del Espacio, con sus diversos componentes diferenciados, deberán confluir los gobiernos (ministerios de Relaciones Exteriores y de Educación), los consejos de universidades y/o de rectores, las propias instituciones universitarias, los organismos internacionales de la Región, las diversas asociaciones y/o redes de universidades existentes así como todos los actores significativos en la educación superior de la región.

Como ya sido señalado, sólo con la construcción de procesos de convergencia en áreas específicas y la posible creación del Espacio Común Latinoamericano, a partir de la identificación de asimetrías, consensos y estrategias, se podrá alcanzar una auténtica articulación convergente con el EEES, tanto en el marco del Espacio ALCUE como en el Iberoamericano.

\section{EL PROYECTO ALFA III CONVERGENCIA}

En el marco de lo expuesto en el punto anterior y bajo la responsabilidad de la Universidad Nacional de Tres de Febrero (UNTREF), se presentó, en el mes de junio de 2008, a la convocatoria de la Comisión Europea ALFA III el Proyecto Convergencia, conjuntamente con una Red de 62 universidades: 46 de América Latina (pertenecientes a 18 países) y 16 de Europa (de 7 países). Asimismo se recibió el apoyo de alrededor de 20 entidades colaboradoras de AL y de Europa -entre ellas el de la Secretaría General Iberoamericana-, el de 8 consejos rectorales y los de diversas redes interuniversitarias y oficinas gubernamentales de Educación Superior, etc. En la Argentina lo avalaron los dos consejos de rectores (el CIN y el CRUP) y la Secretaría de Políticas Universitarias.

El Objetivo General de este Proyecto era el de desarrollar acciones, realizar estudios y generar redes tendientes a promover la convergencia de los sistemas universitarios en cada uno de los países y en el conjunto de la región -favoreciendo la creación de un Espacio Latinoamericano de Educación Superior-, en forma articulada con el Espacio Europeo de Educación Superior y con los objetivos, realizaciones, experiencias y buenas prácticas desarrolladas en el marco del Proceso de Bolonia, todo ello atendiendo los desafíos y las tendencias de la sociedad del conocimiento.

Lamentablemente el proyecto no fue aprobado por la Comisión Europea, quizás no comprendiendo la significación del mismo y la estrategia de construcción del Espacio Común, diferente a la del EEES, como ya ha sido señalado. 


\section{LA RED INTERNACIONAL PARA LA CONVERGENCIA DE LA EDUCACIÓN SUPERIOR (RICES)}

A partir del proyecto Convergencia -no aprobado por la CE-, varias de las universidades que lo integraban le solicitaron a la Universidad Nacional de Tres de Febrero (UNTREF) seguir trabajando juntas en el marco de sus objetivos, particularmente los de promover la convergencia de la Educación Superior en América Latina y de aprovechar la experiencia y las "buenas prácticas" de la Europea y la de sus universidades.

Por ello, actualmente se está organizando - bajo la coordinación de la UNTREF- la Red Internacional para la Convergencia de la Educación Superior (RICES).

El objetivo general de la Red RICES es el de desarrollar acciones, trabajos y estudios conjuntos y promover intercambios académicos tendientes a facilitar la convergencia de los sistemas universitarios en cada uno de los países latinoamericanos y en el conjunto de la región -favoreciendo la creación de un Espacio Latinoamericano de Educación Superior-, en forma articulada tanto con el Espacio Europeo de Educación Superior como con los de otras regiones del mundo, atendiendo a los desafíos y las tendencias de la sociedad del conocimiento. Para alcanzar este objetivo :

- Se desarrollarán trabajos y estudios que favorezcan la convergencia de los sistemas universitarios nacionales, a nivel subregional y del conjunto de América Latina.

- Se promoverá la convergencia entre distintas asociaciones y redes interuniversitarias ya existentes.

- Se estudiarán -conjuntamente con organismos y universidades integrantes de la Red- políticas, buenas prácticas y experiencias positivas desarrolladas en el marco tanto del EEES (Proceso de Bolonia) como del NAFTA y de otras regiones del mundo.

- Se recopilarán, se analizarán y se difundirán los trabajos y estudios desarrollados en América Latina, en América del Norte, en Europa -en particular los producidos por la Comisión Europea (Proyectos ALFA y otros) y en otras regiones, que sean contributivos a los procesos de convergencia.

- Se desarrollarán lineamientos para implementar políticas de convergencia de la Educación Superior, a nivel regional, subregional y nacional, en 
acuerdo con consejos de rectores, redes interuniversitarias, gobiernos y organismos internacionales.

- Se integrará y conformará un amplio repertorio documental digital de acceso abierto sobre los sistemas de educación superior vinculado a la convergencia y sobre los ejes transversales.

Particularmente se promoverán procesos de convergencia en cada país, en cada subregión y en el conjunto de América Latina, en cuanto a:

- Organización de la educación superior y sus normativas;

- Políticas de desarrollo de la educación superior y sus metas de equidad;

- Criterios y estándares de calidad, su evaluación y acreditación;

- Estudios de posgrados y redes y proyectos de investigación;

- Educación a distancia y virtual;

- Internacionalización de la educación superior y educación trasnacional.

Se ha propuesto como ejes transversales (o núcleos orientadores) de los procesos de Convergencia de la Red, los siguientes:

- La estructura organizativa de los sistemas de educación superior, sus marcos normativos de regulación y articulación de ciclos;

-Las políticas y estrategias en materia de desarrollo de la educación superior y sus metas en términos de acceso, equidad y cobertura;

- Los criterios y estándares de calidad y sus sistemas de evaluación y acreditación;

- Las estructuras, el funcionamiento y las características de los estudios de posgrados y de la investigación, propendiendo al diseño de proyectos de carácter cooperativo a nivel de cada país, de subregiones y del conjunto de América Latina;

- Las políticas, estrategias, criterios y estándares en materia de educación a distancia y virtual;

- Las normativas, estrategias y criterios comunes en relación a la internacionalización de la educación superior y a la educación superior de carácter trasnacional, en lo referido al reconocimiento de las certificaciones, el ejercicio laboral docente o profesional, la movilidad estudiantil, la oferta transfronteriza y otras modalidades de la educación internacional. 
A los efectos de esta Red se ha definido convergencia como un funcionamiento armónico y articulado de los sistemas de educación superior, que permita -entre ellos- interacciones, intercambios de recorridos docentes y estudiantiles, reconocimiento mutuo de estudios y títulos, programas y proyectos conjuntos $\mathrm{y}$, en general, una dinámica sistémica y de carácter complementario.

\section{REFERENCIAS}

COMISIÓN EUROPEA. Proyecto "Acreditación y Reconocimientos Oficiales entre Universidades del MERCOSUR y la Unión Europea" (ACRO). Documentos varios.

FERNÁNDEZ LAMARRA, Norberto. Armonización de requerimientos educativos y migratorios entre países del MERCOSUR. Buenos Aires: OIM, julio de 1999. (mimeo).

FERNÁNDEZ LAMARRA, Norberto. La educación superior argentina en debate. Situación, problemas y perspectivas. Buenos Aires: Eudeba-IESALC/UNESCO, mayo de 2003.

FERNÁNDEZ LAMARRA, Norberto. Hacia una nueva agenda para la educación superior. Internacionalización, evaluación de calidad y educación virtual. Alternativas, San Luis. Universidad de San Luis, año IX, n. 37, nov. 2004.

FERNÁNDEZ LAMARRA, Norberto (Coord.). Universidad, sociedad e innovación. Una perspectiva internacional. Proyecto RILEUS. Buenos Aires: EDUNTREF, 2009.

FERNÁNDEZ LAMARRA, Norberto. Modelos y sistemas de evaluación y acreditación de la educación superior. Situación y perspectivas para el mejoramiento de la calidad y la integración regional En: GAZZOLA, Lúcia, Ana; PIRES, Sueli. (Coord.). Hacia una política regional de asseguramiento de la calidad en educación superior para América Latina y el Caribe. Caracas: IESALC/UNESCO, 2008. 
FERNÁNDEZ LAMARRA, Norberto. Educación superior y calidad en América Latina y Argentina. Los procesos de evaluación y acreditación. Buenos Aires: IESALC / UNESCO-EDUNTREF, 2007.

FERNÁNDEZ LAMARRA, Norberto; PULPER, Darío. Educación y recursos humanos en el MERCOSUR. Armonización de políticas para la integración. Buenos Aires: INTAL / BID, dic.1992.

GIL, Luciana; OBAYA, Martin. Las redes universitarias en América Latina y el Caribe. Buenos Aires: Universidad de Bologna, Proyecto VERTEBRALCUE. (mimeo).

GOÑI ZABALA, Jesús. El espacio europeo de educación superior, un reto para la Universidad. Barcelona: Octaedro/ICE-UB, 2005.

IESALC / UNESCO. Documentos en línea. < http://www.iesalc.unesco. org.ve $>$.

IESALC / UNESCO. Informe sobre la educación superior en América Latina y el Caribe, 2000- 2005. La metamorfosis de la educación superior. Caracas, 2006.

LEMEZ, Rodolfo, La construcción y aplicación del mecanismo de acreditación MERCOSUR: fortalezas y debilidades. Montevideo: Proyecto ALFA-ACRO, jun. 2002

MORA, José-Ginés; FERNÁNDEZ LAMARRA, Norberto, (Coord.). Educación Superior. Convergencia entre América Latina - Europa. Proyecto ALFA-ACRO. Comisión Europea. Buenos Aires: EDUNTREF, 2005.

OEI. Documentación sobre programas y actividades. < http://www. oei.org.es>.

OUI. Documentación sobre programas. $<$ http://www.oui.iohe. qc.ca>. 
ROSARIO MUÑOZ, Victor; MARÚM ESPINOSA, Elia; ALVARADO NANDO, Maritza. (Coords.). La autonomía universitaria a debate. Una visión desde América Latina. México: Universidad de Guadalajara, 2010. 